\title{
Termination of the Medieval Warm Period: Linking sub- polar and tropical N Atlantic circulation changes to ENSO
}

Antoon Kuijpers' ${ }^{1}$, B.A. Malmgren², M.-S. Seidenkrantz ${ }^{3}$

'Geological Survey of Denmark and Greenland, Copenhagen, Denmark; aku@geus.dk 2Norrtälje, Sweden; ${ }^{3}$ Department of Earth Sciences, University of Aarhus, Denmark

\begin{abstract}
Paleoceanographic evidence from the N Atlantic subpolar gyre and NE Caribbean indicates a major, longterm change in ocean-atmosphere circulation modes around AD 1230, indicating that the termination of the Medieval Warm Period prevailing circulation mode occurred prior to the Wolf Solar Minimum, apparently without an obvious external trigger.
\end{abstract}

\section{Medieval warming and Little Ice Age climate anomalies}

Historical records and proxy climate data from the Northern Hemisphere have provided evidence for higher average temperatures in the period between ca. $A D$ 800 and $A D$ 1200. The existence of this Medieval Warm Period (MWP) is not only demonstrated by climate data from northern Europe but is also found elsewhere in the Northern Hemisphere. Significant temporal and regional differences did exist however, and the case for a global MWP is more inconclusive than indicated by global records for the following colder era, termed the Little Ice Age (LIA), which spanned the period from ca. AD 1350 to 1850 (Broecker, 2001).

Several theories have been proposed to explain the possible cause of the climate anomalies experienced during the MWP and LIA. Shindell et al. (2001) explained these anomalies by long-term solar variations that modulate the atmospheric circulation. Other mechanisms, such as sulfate aerosols ejected into the atmosphere by volcanic eruptions and changes in large-scale ocean circulation, are also proposed to have played an important role (Broecker, 2000; Crowley, 2000). It has often been reported that variations in sea ice can influence thermohaline circulation (e.g., Mauritzen and Häkkinen, 1997). Such variations in sea ice and polar water (PW) advection have occurred on widely different timescales with periodicities of decades, centuries and millennia, and have had major impacts on North Atlantic climate (e.g., Bond et al., 1997; Andrews et al., 2003). Increased fluxes of low salinity PW may reduce or even shut down deepwater formation in the Nordic Seas, leading to regional cooling. At the same time, however, it may result in significant warm anomalies in thermocline waters of the tropical Atlantic (Dahl et al., 2005). With marine sediment-core data presented below, we underline possible linkages between subpolar and tropical North Atlantic circulation changes associated with the termination of the MWP. This information contributes to a better understanding of polar-tropical Atlantic teleconnections at the transition from a warmer to a colder climate regime.

\section{West Greenland Current changes and medieval cooling}

A recent study of sediment cores collected from West Greenland fjord and shelf environments (Figs. 1, 2A) showed clear evidence for cooling of West Greenland Current water masses at the beginning of the MWP that persisted into the following centuries (Seidenkrantz et al., 2007; 2008). This regional early cooling is also reflected in reduced melt-water production from the West Greenland inland ice margin, as indicated by decreased amounts of the land-derived elements $\mathrm{Ti}, \mathrm{K}$, and Fe measured by XRF-scanning of sediment cores (Møller et al., 2006). Notably, during the same period between ca. AD 730 and AD 1100 , the climate of the eastern Greenland Nansen Fjord region was warmer

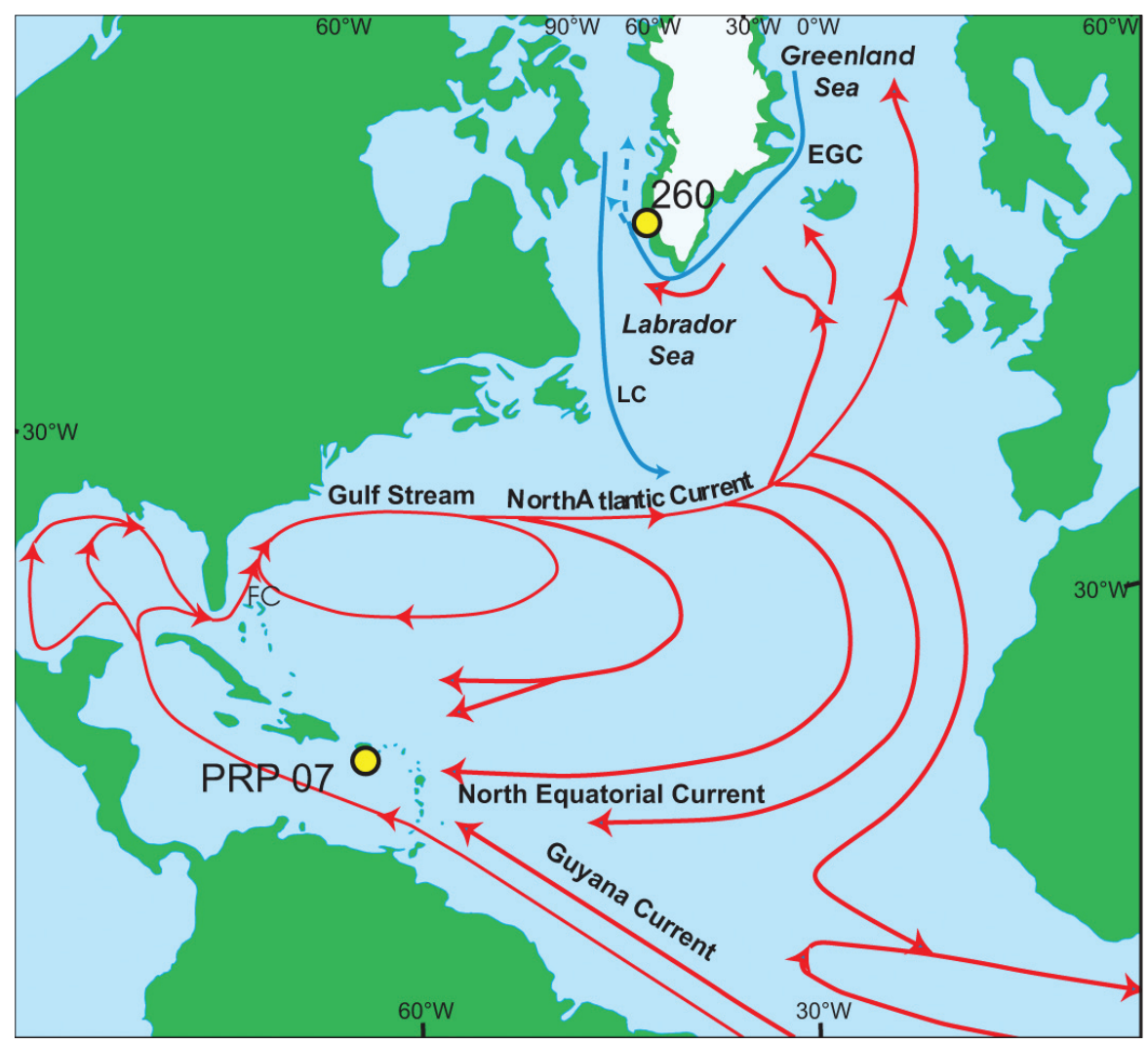

Figure 1: Map of the North Atlantic with location of gravity core 248-260-2 from Ameralik Fjord, SW Greenland and the NE Caribbean study of core PRP-07 (box core and piston core). Blue lines indicate cold Polar Water transport pathways ( $E G C=$ East Greenland Current, $L C=$ Labrador Current); red lines and arrows show the main warm water transport pathways of the North and Equatorial Atlantic. and more stable than today (Jennings and Weiner, 1996), and the GISP2 Greenland ice core record indicates warmer climate conditions than in the following LIA (Stuiver et al., 1995). In comparison, from present climate variability we know that although global average temperature has been rising over the past decades, during the late $20^{\text {th }}$ century, a well-documented cooling prevailed in the Hudson Strait region (Kasper and Allard, 2001). Cooling during the late $20^{\text {th }}$ century has also been reported from coastal southern Greenland and the adjacent Labrador Sea (Hanna and Cappelen, 2003). Immediately after AD 1200 , the sediment core record indicates enhanced subsurface transport of warmer Irminger Sea Water advected by the West Greenland Current (Fig. 2A). Other paleoceanographic evidence of increased subsurface advection of Atlantic water masses elsewhere in South Greenland fjords (Lassen et al., 2004) confirms this LIA feature 
Core 248260

Ameralik Fjord

SW Greenland

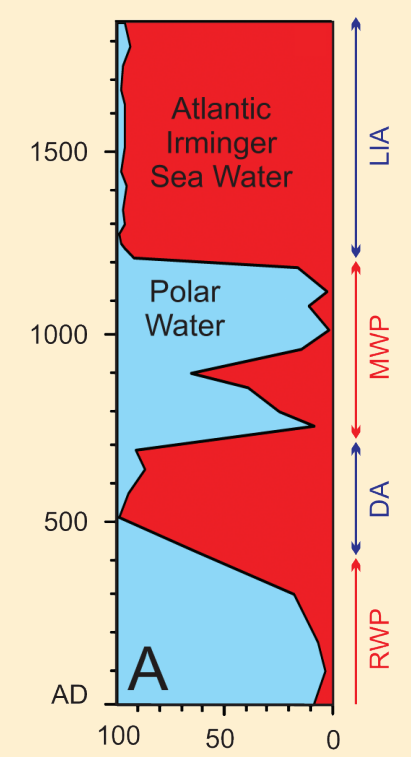

$\%$ calcareous vs.

agglutinated foraminifera strength of ISW advection

Figure 2: A) Variations in the strength of Irminger Sea Water (ISW) transport by the West Greenland Current based on benthic foraminiferal studies of a core from AmeralikFjord, SW Greenland (Seidenkrantz et al., 2007). Note increased ISW transport during colder European (winter) climate of the Dark Ages and Little Ice Age. B) Cold (winter) season (CS) and warm season (WS) SST variations over the southern Puerto Rico insular slope since AD 800 reconstructed for core PRP-07 by the Artificial Neural Networks (ANN) method (Malmgren et al., 2001). RWP= Roman Warm Period, $D A=$ (European) Dark Ages, MWP = Medieval Warm Period, LIA = Little Ice Age, MW = Modern Warming.

to be typically associated with North (East) Atlantic cooling. For the recent climate, it can be shown that warming of the subpolar gyre during the 1950s and most of the 1960s (Levitus et al., 1994) coincided with a generally colder European winter and a more frequent negative North Atlantic Oscillation (NAO). Thus, shortly after AD 1200, Irminger Current water mass transport into the northern Labrador Sea apparently intensified, while sediment diatom records from the southeast Greenland shelf (Jensen, 2003) show a decreased influence of Irminger Sea water for this time.

\section{Northeast Caribbean SST since AD 800}

A 2.70-m-long piston core PRP-07 was retrieved from the southern insular slope of Puerto Rico at $17^{\circ} 52.82^{\prime} \mathrm{N} 66^{\circ} 35.90^{\prime} \mathrm{W}$ (Fig. 1), where water depth is $273 \mathrm{~m}$. At the same site, a 0.20-long box core was collected. Surface-water flow in the region is controlled by interannual and seasonal variability of the North Equatorial Current and Guyana Current. Upper water masses are Caribbean Surface Water and Tropical Atlantic Central Water (TACW; Metcalf, 1976; Wüst, 1964). The inflow of warm, saline TACW into the eastern Caribbean is at a maximum during winter, when the Intertropical Convergence Zone (ITCZ) is far-
Core PRP 07

Puerto Rico, Caribbean

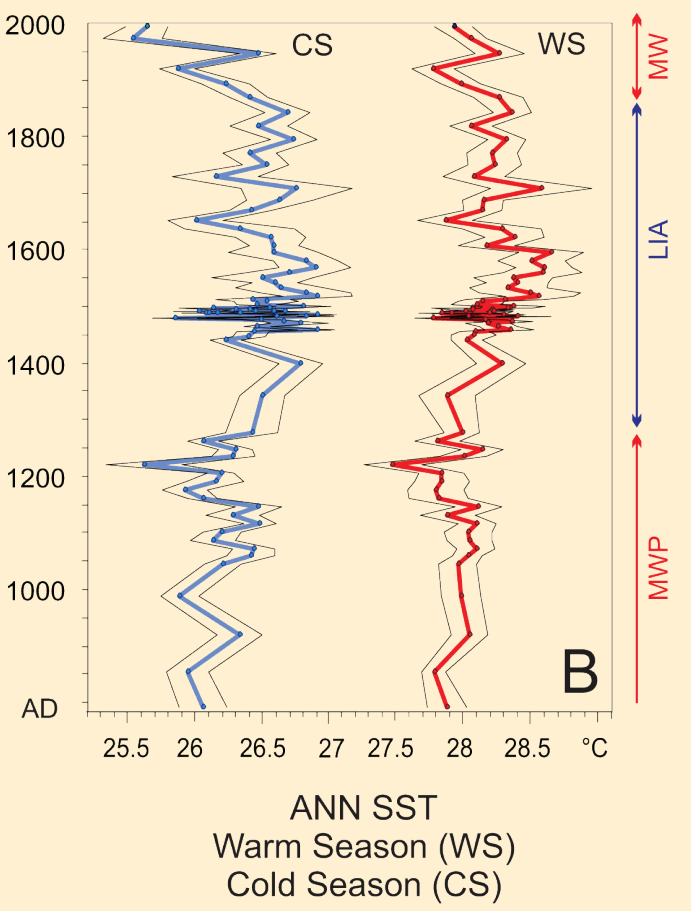

the ITCZ and North Atlantic cyclone belt. Warmer NE Caribbean (winter) SST dominating during the LIA may thus be related to a more southerly ITCZ favoring stronger advection of warm TACW into the area, and favored additionally by positive SST anomalies prevailing east of the Caribbean under a more negative NAO mode.

\section{Subpolar - tropical and ENSO linkage}

Actual ENSO teleconnections imply, amongst other things, colder winter climate over NE Canada and a cooler NE Caribbean during La Niña years. Our sediment core data for the MWP indicate cooling offshore West Greenland and lower NE Caribbean SST prior to ca. AD 1230, suggesting more frequent La Niña years and a positive NAO mode associated with a more northerly ITCZ during the MWP. This supports the study by Mohtadi et al. (2007), who reported southern high-latitude cooling and reduced ENSO activity during the MWP with a sustained northward shift of Southern Hemisphere zonal systems between 1300 and $750 \mathrm{yr}$ BP. After AD 1230, southward movement of the ITCZ favored a more frequent negative NAO mode leading to higher NE Caribbean SST and colder NE Atlantic climate, which can thus be linked to Southern Hemisphere climate changes. As the above changes occurred prior to the Wolf Solar Minimum, ocean-atmosphere circulation modes appear to have the potential of a significant shift without an obvious external trigger, possibly due to non-linear response of the system after surpassing critical boundary conditions.

\section{References}

Bakke, J., Lie, Ø., Dahl, S.O., Nesje, A. and A.E. Bjune, 2008: Strength and spatial patterns of the Holocene wintertime westerlies in the NE Atlantic region, Global and Planetary Change, 60: 28-41.

Broecker, W.S., 2001: Was the Medieval Warm Period global? Science, 291: 1497-1499.

Malmgren, B.A., Winter, A. and D. Chen, 1998: El Nino-Southern Oscillation and North Atlantic Oscillation control of climate in Puerto Rico, American Meteorological Society Notes and Correspondence, October 1998: 2713-2717

Mohtadi, M., Romero, 0.E., Kaiser, J. and D. Hebbeln, 2007: Cooling of the southern high latitudes during the Medieval Period and its effect on ENSO, Quaternary Science Reviews, 26(7-8): 1055-1066.

Seidenkrantz, M.-S., Aagaard-Sørensen, S., Sulsbrück, H., Kuijpers, A., Jensen, K.G. and Kunzendorf, H., 2007: Hydrography and climate of the last 4400 years in a SW Greenland fjord: implications for Labrador Sea palaeoceanography, The Holocene, 17(3): 387401. values between AD 1400 and AD 1850 (LIA). Evidence for a worldwide change in atmospheric circulation change between AD 1200 and AD 1250 is found both in the Southern Hemisphere (Mohtadi et al., 2007) and at northern high latitudes (Lassen et al., 2004; Bakke et al., 2008). This change involves a change in El NiñoSouthern Oscillation (ENSO) boundary conditions, and (southward) migration of
For full references please consult: www.pages-igbp.org/products/newsletters/ref2009_2.html 